\title{
Hemophagocytic Syndrome
}

National Cancer Institute

\section{Source}

National Cancer Institute. Hemophagocytic Syndrome. NCI Thesaurus. Code C35439.

A classification of rare, non-neoplastic, proliferative disorders of the hematologic system. Primary or familial hemophagocytic lymphohistiocytosis $(\mathrm{HLH})$ is inherited with an autosomal recessive pattern with five known subtypes differentiated by specific genetic mutations. Secondary manifestation of HLH is usually seen in hyperactivated immunologic states such as infection, autoimmune disease or malignancy. Histiocytes in the bone marrow, spleen or lymph nodes become activated to the point that phagocytosis proceeds unchecked. Clinical signs usually present within the first decade and include fever, jaundice, hepatosplenomeg aly, lymphadenopathy and skin rash. Prompt initiation of treatment improves survival though prognosis remains poor even with intervention. 